\title{
The Role of Dominant Personality Traits in Multiple Perpetrator Rape Proclivity
}

\author{
Alessia A. Petrella ${ }^{1}$, Leigh Harkins ${ }^{1}$ \\ [1] University of Ontario Institute of Technology, Oshawa, ON, Canada.
}

Sexual Offending: Theory, Research, and Prevention, 2021, Vol. 16, Article e3699, https://doi.org/10.5964/sotrap.3699

Received: 2020-05-11 • Accepted: 2021-03-11 • Published (VoR): 2021-06-15

Handling Editors: Martin Rettenberger, Centre for Criminology (Kriminologische Zentralstelle - KrimZ), Wiesbaden, Germany; L. Maaike Helmus, Simon Fraser University, Burnaby, BC, Canada

Corresponding Author: Alessia A. Petrella, Faculty of Social Sciences and Humanities, University of Ontario Institute of Technology, 2000 Simcoe Street North, Oshawa, ON, L1G 0C5, Canada. E-mail:

Alessiapetrella1@hotmail.com

\begin{abstract}
Background/Aim: Multiple perpetrator sexual assaults (MPSA) often involve more severe forms of sexual violation and result in a host of impairments for the victim. To further investigate the characteristics of MPSA, researchers have taken an interest in personality traits, varying group dynamics, and the role a leader may play. This study examines the possible linkage between dominant personality characteristics and the propensity to engage in multiple perpetrator sexual assault.

Method: Using anonymous online surveys, university student participants were assessed on The Personality Scale for Dominance and the Multiple Perpetrator Rape Proclivity Scale (M-PRIS). We hypothesized that dominant personality traits would predict M-PRIS proclivity score.

Results: Of 176 respondents, 84 heterosexual males completed both measures. Dominance scores did not significantly predict total M-PRIS score, $\mathrm{F}(1,82)=1.1, \mathrm{p}=.296$, the Enjoyment subscale score, $\mathrm{F}(1,82)=.66, \mathrm{p}=.420$, the Likelihood subscale score, $\mathrm{F}(1,86)=1.13, \mathrm{p}=.292$, or the Arousal subscale score, $\mathrm{F}(1,82)=0.66, \mathrm{p}=.419$.

Conclusion: In this study, dominance was not associated with a proclivity for multiple perpetrator sexual violence. Other important factors, such as psychopathy or deviant sexual interests, may mediate the relationship between dominant personality traits and the tendency to initiate a multiple perpetrator sexual assault. Future studies should examine alternative relationships in hopes of gaining a clearer picture of individuals who exhibit a proclivity for sexual violence with the aim to inform prevention and practice.
\end{abstract}




\section{Keywords}

multiple perpetrator sexual assault, personality traits, dominance

\section{Highlights}

- Multiple perpetrator sexual assault (MPSA) is more prevalent than many believe it to be, thus important predictors of MPSA should be empirically investigated.

- Sexual violence is known to be under-reported so proclivity measures can allow us to investigate a propensity towards sexual violence in non-offending populations.

- Leaders are commonly the ones who are responsible for key aspects of MPSAs including initiation and the types of sexual acts involved, thus it was hypothesized that dominant personality traits would play a role in predicting a propensity for MPSA.

- Dominant personality traits were not found to predict MPSA proclivity thus further work is needed to understand the personality characteristics of those who have a propensity for MPSA.

Multiple perpetrator sexual assault is defined as sexual assault of a victim carried out by more than one assailant (Morgan, Brittain, \& Welch, 2012). Such assaults have greater potential to leave a victim with various physical and psychological injuries (Woodhams et al., 2012). Prevalence rates in South Africa, the US and the UK suggest that multiple perpetrator sexual assaults account for a substantial portion of sexual offences committed (Woodhams et al., 2012). Previous research has noted that such assaults often involve more severe forms of sexual violation and result in far reaching implications for the victim in comparison to lone perpetrator sexual assaults (Woodhams et al., 2012). To provide further insight, researchers have taken interest in varying group dynamics and the role a leader may play within this context. It has been noted that leaders within multiple perpetrator sexual assaults play a pivotal role in initiating, mobilizing, and finalizing the act (Woodhams et al., 2012). In attempting to understand the varying dynamics of a leader, the interrelation between leadership and dominance is apparent, where the latter may provide greater insight into the former.

Prevalence rates of multiple perpetrator sexual assault, similarly to lone perpetrator sexual assault, are inconsistent due in part to underreporting. It is estimated that $75 \%$ to 95\% of all rapes [in the United Kingdom (UK)] are not reported to the police (Morgan et al., 2012). Based on the available data, within the UK, approximately $42 \%$ of juvenile sexual assault cases are committed by multiple perpetrators (Woodhams, 2004). Higher prevalence rates are also found within MPSA data from South Africa and the US; with a third to half of all rapes being attributed to more than one assailant in South Africa and approximately 1 in every 10 rapes in the United States (Horvath \& Kelly, 2009). Such prevalence rates do not account for the entirety of sexual assaults and rapes that occur, suggesting that rates are likely substantially higher than statistically presented. Such 
high proportions highlight the apparent need to identify, understand, and prevent such crimes.

Previous research has considered the nature of both lone and multiple perpetrator sexual assault and the distinctions between the two. Researchers have found that group assaults result in more completed rapes in comparison to lone perpetrator assaults, accounting for $88 \%$ for the former and $55 \%$ for the latter (Morgan et al., 2012). A number of varying sexual acts are involved in a group rape, with vaginal penetration being the most common (Morgan et al., 2012). Multiple perpetrator sexual assaults result in substantially higher rates of aggression and physical violence towards the victim, and a heightened likelihood of being threatened with a weapon. (Morgan et al., 2012). For instance, approximately a fifth of all multiple perpetrator victims within the UK reported being threatened with a weapon, with the most common being a knife (Morgan et al., 2012). Degrading behaviors such as sexual humiliation and verbal insults frequently ensue (Morgan et al., 2012).

Researchers analyzed various factors associated with MPSA, including group dynamics (Morgan et al., 2012). They considered how being part of a group influences individual behavior and the heightened likelihood to comply within a group context. In this respect, Morgan and colleagues (2012) took socio-psychological processes into account when attempting to understand why an individual may feel compelled to partake in an act they may not have initiated on their own. Concepts such as deindividuation, diffusion of responsibility and the pressure to conform can all influence an individual's thought process and behavior within group contexts. Harkins and Dixon (2013) also made note of how obedience to authority and social corroboration contribute. In considering the role of individual interactions, and the socio-cultural and situational context, Harkins and Dixon (2013) created a multi-factorial approach to analyze the role several factors (namely individual, socio-cultural, and situational) play in partaking in such an offence.

As several theories have focused on the effects of group dynamics, researchers have also given thought to the influence a leader has on individuals within a group. Previous research has noted the existence of a clear leader within groups that commit MPSA (Woodhams et al., 2012). Bijleveld, Weerman, Looije, and Hendriks (2007) conducted a study on juvenile offenders from the Netherlands and were able to identify a leader in one third of the participants. Porter and Alison (2001) conducted a similar study with US offenders and were able to identify a leader within 37 of the 39 offences under review. Although it is important to note that some multiple perpetrator rapes occur without the influence of a leader, leaders who are identified within the group play a pivotal role in planning and committing an offence (Woodhams et al., 2012).

Although previous studies have provided prodigious detail on characteristics of both leaders and followers, a recent study by 't Hart-Kerkhoffs and colleagues (2011) on juvenile multiple perpetrator rapes failed to identify the expected differences between the two. Each offender was classified based on The Global Assessment Instrument 
for Juvenile Sexual Offenders as either a leader, follower, or neither. Discrepancies in classifications were noted as the likely cause of the non-significant findings and a need for reliable and valid measures of leaders and followers were highlighted (Woodhams et al., 2012). The need for such classifications stemmed from findings that suggest characteristic differences in leaders and followers. Leaders are seen as more delinquent, exhibit severe conduct problems and have a greater risk of reoffending, whereas followers were characterized by higher levels of social impairment and lack of resistance to group pressure (Woodhams et al., 2012). Woodhams and colleagues (2012) reported that leaders "played a significant role in finalizing and mobilizing the group's intent" (p. 730). Leaders within a group are usually the ones to direct the group's attention onto sexual matters as their sexual feelings are stimulated by the presence of others (Woodhams et al., 2012). They are also more likely to initiate violence towards the victim. It has been suggested that without a leader present, many rapes would not have occurred as reaching a consensus to this degree would be difficult (Woodhams et al., 2012).

In an attempt to attain a more comprehensive understanding of a leader, dominance (as a characteristic) should be considered. In their study, Anderson and Kilduff (2009) explain why dominant personalities attain influence in face-to-face groups. These authors suggest that individuals high in trait dominance exert influence because they are viewed as more competent by others. Dominance is identified as involving the tendency to behave in assertive, forceful, and self-assured ways (Anderson \& Kilduff, 2009). Individuals higher in this specific trait are seen to assert more control in group contexts, are more vocal than other group members, and hold higher influence when making decisions (Anderson \& Kilduff, 2009). In a meta-analysis, trait dominance was a consistent predictor of who would emerge as a leader, more so than other individual traits, including intelligence (Anderson \& Kilduff, 2009).

As individuals cannot take complete charge over others by force, they require social competencies in order to persuade others within the group (Anderson \& Kilduff, 2009). Anderson and Kilduff (2009) used task groups and outside observers to test their hypothesis. During group discussions, they used a social relations model analysis of peer ratings of competence and influence (Anderson \& Kilduff, 2009). As they predicted, trait dominance predicted perceptions of task competence and social competence by other group members (Anderson \& Kilduff, 2009). Outside observer ratings also supported this finding. They then measured discrete behaviors that they considered to convey competence. Higher frequencies of 'competence-signaling behaviors' were expected to be displayed by dominant individuals confirming the ideology that they overtly display competency more so than others (Anderson \& Kilduff, 2009). As hypothesized, individuals high in trait dominance indeed displayed more competence through their behaviors and therefore were perceived in this light by other group members and from outside observers, despite their actual ability (Anderson \& Kilduff, 2009). 
Dominance is also relevant in understanding sexual violence. A study analyzing deviance in college samples noted that college perpetrators are more likely to have a need for dominance and power over others and have a higher tendency to adhere to extreme masculine gender roles (Mouilso \& Calhoun, 2012). Pourban (2014) used The Personality Assessment Inventory (PAI) Dominance Scale and found considerably higher rates of dominance for individuals convicted of sexually violent offences compared to the general public.

As characteristics of leadership hold power within a group, we can see how individuals that fall into the 'follower' category may feel pressured to comply. Followers may be emotionally dependent on the leader or feel irresponsible for their actions if they were directed to act rather than deciding to on their own (Woodhams et al., 2012). Consequences for non-conformity may follow if they decide to go against a leader's directive. The possibility of both being victimized themselves and being excluded from the group may be reason enough for someone to simply comply (Woodhams et al., 2012). As a clear vulnerability lies within the follower, it has been suggested that differing interventions should exist for each group. Interventions incorporating both leaders and followers may be problematic in terms of receiving fair and adequate treatment. Leaders may intimidate or threaten non-assertive individuals and encourage denial or minimization of the offence (Woodhams et al., 2012). Researchers have examined the criminogenic needs of leaders and followers and have suggested tailoring intervention to suit these needs (Woodhams et al., 2012). As leaders are at a greater risk of reoffending, treatment should be seen as a priority, with them being encouraged to accept their status within the group and engage in the intervention.

\section{Current Study}

In previous research, dominant characteristics have been identified within leaders, and have played a role in influencing individuals to engage in sexual violence. Given that sexual violence, including multiple perpetrator rape is under-reported, measures of rape proclivity are often used to study these types of crimes. Proclivity measures allow for potentially problematic interests to be examined in the general (i.e., non-offender) population, or even possibly, those who have committed such offenses but have not been caught. These measures assess both individuals' self-reported interest in and likelihood of engaging in sexually violent behavior such as MPSA (e.g., Blake \& Gannon, 2010; Bohner et al., 1998). Thus, this study aims to examine the role of dominance traits in MPSA proclivity. This will be examined through determining whether dominance traits, assessed by the Personality Scale for Dominance (Gough, McClosky, \& Meehl, 1951) predict MPSA proclivity, assessed by the Multiple Perpetrator Rape Interest Scale (M-PRIS; (Alleyne, Gannon, Ó Ciardha, \& Wood, 2014). It is hypothesized the dominance score will predict level of proclivity for multiple perpetrator sexual violence. 


\section{Method}

\section{Participants}

Following ethical approval from UOIT's review board, data were collected from 448 anonymous university students who consented to complete an online survey that assessed factors related to deviant sexual interests and proclivity. Students were recruited through their psychology courses and were offered an opportunity to participate in a research study of their choice to gain extra credit. Of the 448, 176 participants identified as heterosexual males and of those, 84 completed both the M-PRIS subscales and the Personality Scale of Dominance.

Of the heterosexual males $(n=84)$, the majority identified as Caucasian males $(n=36$, $42.9 \%$ ) or South East Asian ( $n=15,17.9 \%$ ). The age of participants ranged from 17 to 32 years $(M=20.4, S D=3.0)$. Participants were also asked how many female sexual partners they have previously had. Of the 84 respondents, the number of sexual partners ranged from 0 to $30(M=2.5, S D=4.5)$. The modal number of respondents reported having no prior sexual partners $(n=31,37.3 \%)$. To follow, $26.5 \%$ respondents reported having 1 prior sexual partner $(n=22)$.

\section{Procedure}

Upon signing up for the study, participants were emailed a consent form describing the study and providing additional information about the participation process. Participants were then emailed a link for the survey which they would complete at their leisure online through Qualtrics. The survey was designed to assess male sexual arousal, motivations, intent and likelihood of the commission of a multiple perpetrator sexual offence. For this particular study, measures of dominance and multiple perpetrator rape proclivity were examined.

\section{Measures}

To assess dominance traits, The Personality Scale for Dominance was utilized, which analyzes personality traits rather than specific instances of leadership related to deviant behaviour. The Multiple Perpetrator Rape Interest Scale (M-PRIS) allows for a greater understanding of the likelihood of participation in a multiple perpetrator sexual assault.

\section{The Personality Scale for Dominance}

This measure (Gough, McClosky, \& Meehl, 1951) is a 60 item agree/disagree survey which assessed self-reported dominant personality traits. Questions assessed participants' thoughts pertaining to their own assertiveness and leadership qualities, as well as measured dominance and alternatively, submissiveness. The scale yielded a Cronba- 
ch's alpha of .70, demonstrating acceptable reliability in the original study. Within this particular study, a Cronbach's alpha of .70 was also found.

\section{The Multiple Perpetrator Rape Interest Scale (M-PRIS)}

The M-PRIS (Alleyne et al., 2014) was derived from multiple perpetrator rape literature and the Rape Proclivity Scale proposed by Bohner et al. in 1998. This vignette- based measure is designed to assess male sexual arousal to multiple perpetrator rape, their behavioral propensity toward, and enjoyment of multiple perpetrator sexual assault (Alleyne et al., 2014). The scale consists of 6 hypothetical scenarios illustrating heterosexual multiple perpetrator rape situations. The scenarios are divided, where three illustrate the initiation of a new member to a group through the use of multiple perpetrator sexual assault, and the remaining three depict the use of multiple perpetrator rape to intimidate the victim. Participants read each scenario and envision themselves as the protagonist. Each scenario is followed by three questions that measure the respondent's arousal to the situation, likelihood of engagement, and their perceived enjoyment. These 18 questions are answered using a 7-point Likert-type scale. Alleyne and her colleagues (2014) found their measure to have high internal consistency (all $\alpha$ coefficients $>.80$ ) and test-retest reliability (all correlations $>.80$ ).

\section{Data Analysis}

Analyses were conducted to measure the relationship between dominant personality traits and M-PRIS scores. Using SPSS (V24, IBM), descriptive statistics were used to provide an overview of the data. A linear regression was used to determine whether ratings of dominance predicted the multiple perpetrator rape proclivity.

\section{Results}

The mean M-PRIS score was $17.9(S D=11.5)$, and the mean Personality Scale of Dominance was $86.7(S D=6.2)$. In terms of MPSA proclivity, $48.8 \%(n=41)$ of the sample showed some level of proclivity (i.e., they indicated something other than 'absolutely no' on one of the questions) and 51.1\% $(n=43)$ did not. The mean Personality Scale for Dominance score was relatively low. Correlations between dominance and MPSA proclivity are included in Table 1 . The dominance scale was not significantly correlated with any of the M-PRIS scales. When comparing those with and without proclivity using a $t$-test there was not a significant difference in relation to dominance, $t(82)=-0.4$, $p=.690$. 
Table 1

Correlations Between Dominance and MPSA Proclivity Scales

\begin{tabular}{lccccc}
\hline Scale & $\begin{array}{c}\text { Dominance } \\
\text { Scale }\end{array}$ & $\begin{array}{c}\text { Enjoyment } \\
\text { Subscale }\end{array}$ & $\begin{array}{c}\text { Likelihood } \\
\text { Subscale }\end{array}$ & $\begin{array}{c}\text { Arousal } \\
\text { Subscale }\end{array}$ & $\begin{array}{c}\text { M-PRIS Total } \\
\text { Scale }\end{array}$ \\
\hline Dominance Scale & 1 & -.089 & -.166 & -.089 & -.115 \\
Enjoyment Subscale & -.089 & 1 & $.579^{*}$ & $.694^{*}$ & $.906^{*}$ \\
Likelihood Subscale & -.116 & $.579^{*}$ & 1 & $.430^{*}$ & $.779^{*}$ \\
Arousal Subscale & -.089 & $.694^{*}$ & $.430^{*}$ & 1 & $.845^{*}$ \\
M-PRIS Total Scale & -.115 & $.906^{*}$ & $.779^{*}$ & $.845^{*}$ & 1 \\
\hline
\end{tabular}

${ }^{*} p<.05$.

A linear regression was then used to determine whether dominance scores predicted MPSA proclivity total score and the three separate subscales: Enjoyment, Likelihood, and Arousal. Dominance scores did not significantly predict total M-PRIS Enjoyment subscale score, accounting for only $0.08 \%$ of the variance of the MPRIS Enjoyment score, $F(1,82)$ $=0.66, p=.420$. Dominance was not a significant predictor of the likelihood to become involved in an MPSA, $F(1,82)=1.13, p=.292$, and accounted for only $1.4 \%$ of the variance. Dominance was not a significant predictor of the likelihood to become aroused during an MPSA, $F(1,82)=0.66, p=.419)$ and accounted for $0.08 \%$ of variance in the model. Ultimately, dominance was not a significant predictor of the total M-PRIS score, $F(1,82)=$ $1.1, p=.296$.

\section{Discussion}

In this study, we investigated whether heterosexual males with and without a MPSA proclivity differed in terms of dominance and if individuals with dominant traits have higher multiple perpetrator sexual assault proclivities. We expected that dominance would be a strong predictor of the expected likelihood, arousal, and enjoyment for multiple perpetrator sexual assault. However, our findings showed that personality traits indicative of dominance were not a significant predictor. That is to say, higher levels of dominant personality traits did not predict an increased proclivity to commit MPSA.

With the exception of a single outlier, all participants who had low dominance traits also had a low M-PRIS score and there was a tendency for those with greater proclivity to have a higher dominance score, but this relationship was not significant. However, this may be because the data lacked variability, in that most data were at the lowest M-PRIS scores possible, exhibiting no to very little proclivity (i.e., floor effect). Thus, it is possible that given a more diverse group of subjects with a greater range of proclivity we may see a significant relationship with dominance. 
Previous research found that leadership relates to multiple perpetrator proclivity (Woodhams et al., 2012). For this reason, we chose to consider dominance as a main factor for committing such crimes. The Personality Scale of Dominance lists multiple statements that attempt to distinguish individuals who have high ratings in dominance. However, the Personality Scale of Dominance may not have been a sufficiently discerning measure. This measure was selected as it was relatively brief, free to access, and relatively simple to score. However, in examining some of the questions further, some are somewhat vague which might limit participants' ability to picture themselves in specific situations that the test alludes to. The PAI Dominance Scale has been used previously by Pourban (2014) who found higher levels of dominance in individuals convicted of sexual violence compared to the general public, thus this measure should be considered in future studies and it might better assess dominance.

Another possibility is that other factors may play a more important role in predicting MPSA proclivity. For example, several studies have found that rape supportive cognitions predicted MPSA (Alleyne et al., 2014; Palermo, Dadgardoust, Caro Arroyave, Vettor, \& Harkins, 2019). This is also consistent with the findings of Bohner and colleagues (1998, 2005) and Malamuth, Sockloskie, Koss, and Tanaka, 1991, who found that those who report higher rape proclivity in general have higher rape supportive cognitions. Thus, it may be the case that such cognitions are playing a much more important role than dominance traits. Additionally, other personality factors, such as psychopathy (which includes personality traits such as being conning and manipulative, pathological lying, and superficial charm), may also be playing a more significant role (Hare, 2003). The combination of psychopathy and deviant sexual interests is one of the strongest predictors of sexual violence (e.g., Hart, 1998) so this is worthy of investigation for the potential role these characteristics may play in MPSA. Those with psychopathic traits may be more likely to be part of or instigate an MPSA.

\section{Limitations and Future Directions}

Several limitations must be noted. For one, the proportion of the sample with complete data was relatively small. Out of 176 heterosexual male respondents, only 84 completed all M-PRIS subscales and dominance measures. It is expected that this was because participants were able to complete the study at home so many may have chosen not to complete the questionnaires. The study could be improved by having participants attend a formal lab to complete the survey. A formal lab component may increase completion rates and provide participants with an opportunity to seek clarification. Another limitation already noted was the dominance measure selected. Another measure may have provided a better assessment of these traits. It should be noted that the participants in this study were university students from a relatively small North American university and thus may not be representative of the wider population in terms of age, ethnicity, culture, education level, etc. Finally, it must be noted that although some participants 
reported that they would be aroused by, likely to engage in, or would enjoy being involved in MPSA scenarios, it is possible that they would not actually engage in MPSA if given the opportunity.

Although these preliminary results did not find dominance to have a significant association with MPSA, future studies should examine this relationship with consideration of other characteristics that may serve as mediators. Literature to date has identified behavioural, attitudinal, and characteristic differences between perpetrators and non-perpetrators of MPSA (Mouilso \& Calhoun, 2012). Similar differences have also been noted between leaders and followers within a group as described above. Better identification of these differences can be utilized in prevention strategies and will ideally translate into better assessment of needs to assist in treatment of both leaders and followers of MPSA offenses.

\section{Conclusion}

The study set out to assess the possible link between dominance and proclivity towards multiple perpetrator rape. The findings of this study did not show such a relationship. In general, participants in this study had low M-PRIS scores and this may have led to a floor effect which could account for this lack of a relationship in the current study. Further investigation of this relationship would benefit from a more diverse group of study participants and efforts to increase complete response rates from participants. Future research should also consider additional factors such as other types of leadership qualities, psychopathy, and deviant sexual interests which may have stronger associations with MPSA proclivity.

Funding: The authors have no funding to report.

Acknowledgments: The authors have no additional (i.e., non-financial) support to report.

Competing Interests: The authors have declared that no competing interests exist.

Data Availability: The data for this study will be available upon request from the corresponding author.

\section{References}

Alleyne, E., Gannon, T. A., Ó Ciardha, C., \& Wood, J. L. (2014). Community males show multipleperpetrator rape proclivity: Development and preliminary validation of an interest scale. Sexual Abuse, 26(1), 82-104. https://doi.org/10.1177/1079063213480819

Anderson, C., \& Kilduff, G. J. (2009). Why do dominant personalities attain influence in face-to-face groups: The competence-signaling effects of trait dominance. Journal of Personality and Social Psychology, 96(2), 491-503. https://doi.org/10.1037/a0014201 
Bijleveld, C. C. J. H., Weerman, F. M., Looije, D., \& Hendriks, J. (2007). Group sex offending by juveniles: Coercive sex as group activity. European fournal of Criminology, 4, 5-31. https://doi.org/10.1177/1477370807071728

Blake, E., \& Gannon, T. A. (2010). The implicit theories of rape-prone men: An informationprocessing investigation. International fournal of Offender Therapy and Comparative Criminology, 54(6), 895-914. https://doi.org/10.1177/0306624X09347732

Bohner, G., Jarvis, C. I., Eyssel, F., \& Siebler, F. (2005). The causal impact of rape myth acceptance on men's rape proclivity: Comparing sexually coercive and noncoercive men. European fournal of Social Psychology, 35, 819-828. https://doi.org/10.1002/ejsp.284

Bohner, G., Reinhard, M.-A., Rutz, S., Sturm, S., Kerschbaum, B., \& Effler, D. (1998). Rape myths as neutralizing cognitions: Evidence for a causal impact of anti-victim attitudes on men's selfreported likelihood of raping. European fournal of Social Psychology, 28, 257-268. https://doi.org/10.1002/(SICI)1099-0992(199803/04)28:2<257::AID-EJSP871>3.0.CO;2-1

Gough, H. G., McClosky, H., \& Meehl, P. E. (1951). A personality scale for dominance. fournal of Abnormal and Social Psychology, 46(3), 360-366. https://doi.org/10.1037/h0062542

Hare, R. D. (2003). The Hare Psychopathy Checklist-Revised (PCL-R) (2nd ed.). Toronto, ON, Canada: Multi-Health Systems.

Harkins, L., \& Dixon, L. (2013). A multi-factorial approach to understanding multiple perpetrator sexual offending. In T. Gannon \& J. Wood (Eds.), Crime and crime reduction: The importance of group processes (pp. 75-95). New York, NY, USA: Routledge.

Hart, S. D. (1998). The role of psychopathy in assessing risk for violence: Conceptual and methodological issues. Legal and Criminological Psychology, 3, 121-137. https://doi.org/10.1111/j.2044-8333.1998.tb00354.x

Horvath, M. A. H., \& Kelly, L. (2009). Multiple perpetrator rape: Naming an offence and initial research findings. Journal of Sexual Aggression, 15(1), 83-96. https://doi.org/10.1080/13552600802653818

Malamuth, N. M., Sockloskie, R., Koss, M., \& Tanaka, J. S. (1991). Characteristics of aggressors against women: Testing a model using a national sample of college students. fournal of Consulting and Clinical Psychology, 59(5), 670-681. https://doi.org/10.1037/0022-006X.59.5.670

Morgan, L., Brittain, B., \& Welch, J. (2012). Multiple perpetrator sexual assault: How does it differ from assault by a single perpetrator? Journal of Interpersonal Violence, 27(12), 2415-2436. https://doi.org/10.1177/0886260511433514

Mouilso, E., \& Calhoun, K. S. (2012). Narcissism, psychopathy and Five-Factor Model in sexual assault perpetration. Personality and Mental Health, 6(3), 228-241. https://doi.org/10.1002/pmh.1188

Palermo, A. M., Dadgardoust, L., Caro Arroyave, S. C., Vettor, S., \& Harkins, L. (2019). Examining the role of pornography and rape supportive cognitions in lone and multiple perpetrator rape proclivity. Journal of Sexual Aggression, 25(3), 244-257.

https://doi.org/10.1080/13552600.2019.1618506 
Porter, L. E., \& Alison, L. J. (2001). A partially ordered scale of influence in violent group behavior: An example from gang rape. Small Group Research, 32(4), 475-497. https://doi.org/10.1177/104649640103200405

Pourban, T. (2014). Sexually violent offender assessment with the personality assessment inventory's dominance/warmth scale, antisocial, egocentric and aggressive-attitude subscales (Doctoral thesis, The University of the Rockies, Denver, CO, USA). Available from ProQuest Dissertations Publishing. (UMI No. 3630051)

't Hart-Kerkhoffs, L. A., Vermeiren, R. R. J. M., Jansen, L. M. C., \& Doreleijers, T. A. H. (2011). Juvenile group sex offenders: A comparison of group leaders and followers. fournal of Interpersonal Violence, 26(1), 3-20. https://doi.org/10.1177/0886260510362882

Woodhams, J. (2004). Characteristics of juvenile sex offending against strangers: Findings from a non-clinical study. Aggressive Behavior, 30, 243-253. https://doi.org/10.1002/ab.20053

Woodhams, J., Cooke, C., Harkins, L., \& da Silva, T. (2012). Leadership in multiple perpetrator stranger rape. fournal of Interpersonal Violence, 27(4), 728-752.

https://doi.org/10.1177/0886260511423244

IATSO

International Association for the
Treatment of Sexual Offenders

Sexual Offending: Theory, Research, and Prevention (SOTRAP) is the official journal of the International Association for the Treatment of Sexual Offenders (IATSO).
(P) leibniz-psychology.org

PsychOpen GOLD is a publishing service by Leibniz Institute for Psychology (ZPID), Germany. 